\title{
The next step in pre-salt exploration: A Seismic design and modeling perspective
}

Franck Le Diagon*1, Jeff Thompson ${ }^{1}$, Luis Arechiga Salinas ${ }^{1}$ and Fernando Alvarez ${ }^{1}$, ${ }^{1}$ Schlumberger

Copyright 2021, SBGf - Sociedade Brasileira de Geofísica.

This paper was prepared for presentation during the $17^{\text {th }}$ International Congress of the Brazilian Geophysical Society held in Rio de Janeiro, Brazil, $16-19$ August 2021.

Contents of this paper were reviewed by the Technical Committee of the $17^{\text {th }}$ International Congress of the Brazilian Geophysical Society and do not necessarily represent any position of the SBGf, its officers or members. Electronic reproduction or storage of any part of this paper for commercial purposes without the written consent of the Brazilian Geophysical Society is prohibited.

\section{Summary}

Most seismic exploration surveys in the Brazilian presalt were acquired with single-vessel narrow-azimuth configurations. We discuss the reasons for this limitation and the steps required for the emergence of multi-vessel wide-azimuth programs. This discussion is supported by a rigorous analysis of seismic modeling experiments.

\section{Results and conclusions}

The Brazilian pre-salt is a deep carbonate layer covered by a thick salt formation located in Santos and Campos basins. Minor discoveries in the pre-salt occurred during the 1980s. With advances in drilling technologies, the province emerged as an exploration frontier in the 2000s and today represents more than $70 \%$ of Brazilian oil production. Most pre-salt exploration surveys were acquired with single vessels towing two seismic sources and multiple streamers, recording a very narrow range of azimuths, because the regulatory agency restricts the number of vessels and sources due to concerns of the impact on marine life. Streamer length, which controls the inline source to receiver offset, has evolved from $\sim 6 \mathrm{~km}$ (post-salt targets) to $\sim 8 \mathrm{~km}$ (presalt targets) and recently $\sim 10 \mathrm{~km}$, contrasting with the short crossline offsets of these narrow-azimuth (NAZ) geometries. With the development of seismic marine sources designed to reduce the impact on marine life, it is now possible to acquire multi-vessel surveys with reduced environmental concerns. We present the modelling results of a proposed multivessel acquisition solution for the Brazilian pre-salt. To evaluate the proposed acquisition design, seismic synthetic experiments were undertaken in two geologically distinct areas of the pre-salt. The first, in Santos Basin, is characterized by a thick section of relatively gentle structured evaporites layers, while the second, in Campos Basin, is dominated by complex homogeneous salt structures with nearvertical walls and overhangs. Fifteen acquisition scenarios were modeled and migrated to produce subsurface images of both areas. The single-vessel configurations were simulated along different azimuths with streamer lengths varying from 6 to 12 $\mathrm{km}$ and represent existent and conceptual NAZ surveys. Some NAZ experiments were merged to simulate a second group of conceptual multi-azimuth (MAZ) surveys. A third group consisted of the proposed multi-vessel scenarios, simulated as wideazimuth geometries (WAZ) along different directions. Each WAZ design is formed by four vessels aligned in the crossline direction. The external vessels tow a single source and multiple streamers whilst the central vessels tow a single source.

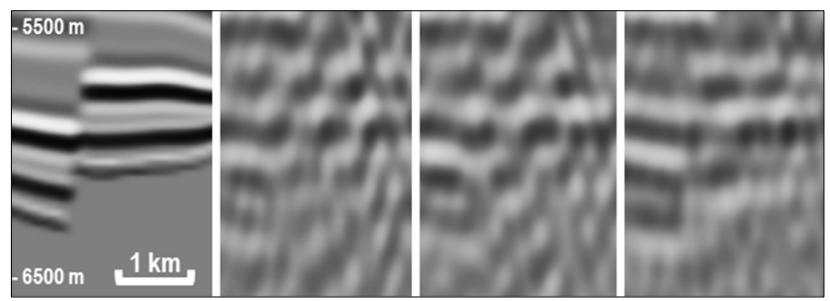

Figure 1: A pre-salt section extracted from seismic synthetic images. From left to right: (a) Model reflectivity, (b) NAZ $6 \mathrm{~km}$ offset, $33^{\circ}$ azimuth, (c) NAZ $10 \mathrm{~km}$ offset, $90^{\circ}$ azimuth, and (d) WAZ (Courtesy WesternGeco).

On analysis of the pre-salt synthetic images (Figure 1) we conclude that: small incremental uplifts were observed on NAZ images after successively increasing the streamer length, adjusting the survey direction and combining azimuths. The group of multi-vessels WAZ geometries delivered significant improvements in fault delineation, structural definition and signal-to-noise ratio. These improvements are directly related to the geometry's higher fold and azimuthal distribution. Additionally, the resulting WAZ images appear less sensitive to survey orientation, which favors the implementation of large exploration surveys increasing efficiency and thus reducing costs. Further analyses are underway to evaluate the potential benefit of simultaneously shooting WAZ sources onto sparse ocean bottom nodes for model building purpose.

The authors thank WesternGeco for permission to publish this paper. 